\title{
Effects of Growth Factors and the MicroRNA- 183 Family on Differentiation of Human Bone Marrow-Derived Mesenchymal Stem Cells Towards Auditory Neuron-Like Cells
}

This article was published in the following Dove Press journal:

Stem Cells and Cloning: Advances and Applications

\author{
Gholamreza Farnoosh' \\ Mohammad- \\ Reza Mahmoudian-Sani (D) ${ }^{2}$ \\ 'Applied Biotechnology Research Center, \\ Baqiyatallah University of Medical \\ Sciences, Tehran, Iran; ${ }^{2}$ Thalassemia and \\ Hemoglobinopathy Research Center, \\ Health Research Institute, Ahvaz \\ Jundishapur University of Medical \\ Sciences, Ahvaz, Iran
}

Introduction: Hearing Loss (HL) is known as the most common sensory processing disorder across the world. An effective treatment which has been currently used for patients suffering from this condition is cochlear implant $(\mathrm{CI})$. The major limitation of this treatment is the need for a healthy auditory neuron (AN). Accordingly, mesenchymal cells (MCs) are regarded as good candidates for cell-based therapeutic approaches. The present study aimed to investigate the potentials of human bone marrow-derived mesenchymal stem cells (hBMMSCs) for differentiation towards ANs along with using treatments with growth factors and microRNA (miRNA) transfection in vitro.

Methods: To this end, neurospheres derived from hBM-MSCs were treated via basic fibroblast growth factor (bFGF), neurotrophin-3 (NT-3), and brain-derived neurotrophic factor (BDNF) as growth factors N2 and B27 supplements, as well as miRNA-96, -182, -183 transfected into hBM-MSCs in order to evaluate the differentiation of such cells into ANs.

Results: Treatments with growth factors demonstrated a significant increase in neurogenin 1 (Ngn1) and sex determining region Y-box 2 (SOX2) markers; but tubulin, microtubuleassociated protein 2 (MAP2), and GATA binding protein 3 (GATA3) markers were not statistically significant. The findings also revealed that miRNA-182 expression in miRNA183 family could boost the expressions of some AN marker (ie, Ngn1, SOX2, peripherin, and nestin) in vitro.

Discussion: It can be concluded that miRNA is probably a good substitute for growth factors used in differentiating into ANs. Transdifferentiation of hBM-MSCs into ANs, which does not occur under normal conditions, may be thus facilitated by miRNAs, especially miRNA-182, or via a combination of miRNA and growth factors.

Keywords: microRNA-183 family, auditory neuron, human bone marrow-derived mesenchymal stem cell, growth factor

\section{Introduction}

Hearing Loss (HL) is known as the most common sensory processing disorder across the world, affecting as many as 360 million people, approximately $3.5 \%$ of the world's population, one-third of whom are subjected to moderate-to-severe deafness. ${ }^{1-3}$ The Cochlear Implant (CI), as an electronic device that directly stimulates Auditory Neurons (ANs.), is an effective treatment which has been currently used for patients
Correspondence: Mohammad-Reza Mahmoudian-Sani

Tel +98 6I-33750410

Fax +98 6I-33750427

Email mohamadsani495@gmail.com
Stem Cells and Cloning: Advances and Applications 2020:13 79-89 
suffering from this condition. ${ }^{4,5}$ However, a major limitation for the use of CIs is the need for a healthy AN. In mammals, neurodegeneration is irreversible. Actually, damaged ANs are usually not replaced by healthy cells as they develop after the mitotic phase. ${ }^{6}$ Accordingly, creating a cell-based therapy is assumed as an appropriate option for designing a sensory and neurological hearing treatment. Some studies have been thus designed for the transdifferentiation of types of non-sensory cells of the inner ears into ANs through their genetic manipulation. For this purpose; increasing the Ngn1 transcription factor expression, a major gene for differentiating into ANs, is considered as a good candidate. With regards to stem cell-based therapies, the present study has focused on the use of external cells (ie, cells outside the auditory system) and their differentiation into ANs. Since stem/progenitor cells no longer exist in mammals' cochlea after birth, ${ }^{7}$ potentials of a wide variety of multipotent progenitor cells were tested for differentiation into sensory cells of the inner ear in vitro and in vivo. ${ }^{8,9}$ It should be noted that embryonic stem cells are associated with a high degree of phenotype plasticity, but a few issues exist such as ethical problems of human embryonic stem cells and other important concerns, such as the possibility of immune responses to onset differentiation and risks of tumor formation. ${ }^{10,11}$ Mesenchymal Stem Cells (MSCs) are other types of adult stem cells that are endowed with potentials for repairing damaged cells. The MSCs are known as multipotent cells with a potential for ex vivo conditions. Besides, they are deemed as good candidates for cellbased therapeutic approaches. There are, however, insufficient studies on the differentiation of MSCs into types of sensory cells of the inner ear. ${ }^{12}$ In vitro studies have also reported that mice MSCs have differentiated into neurons. ${ }^{13}$ In spite of this, there is little information about human MSCs, which motivated this study to investigate the potentials of human Bone Marrow-derived Mesenchymal Stem Cells (hBM-MSCs) for the development of ANs using treatments with growth factors and miRNA transfection in vitro.

\section{ANs and Spiral Ganglion Cells}

The ANs are associated with a set of bipolar hearing nerves creating synapses peripherally with hair cells and centrally with cochlear ones. Spinal ganglia cells are also cellular objects of ANs, ${ }^{14}$ which extend from the temporal bone to the stem of the brain. The spiral ganglion cells, or the cells of the ANs, are also located in Rosenthal's canal, their dendrites are located around, and their axons are at the center. ${ }^{15}$ In parallel to hair cells and other structures of the inner ears with unique anatomical characteristics in the area of $\mathrm{AN}$ repair, ANs play an important role in hearing return in medicine. ${ }^{16}$ The AN in which auditory neurodegeneration occurs is further seen in numerous clinical disorders and among the elderly. This pathologic condition is thus regarded as an appropriate option for cell transplantation, since remaining live hair cells can provide nutritional factors for transplanted ones. ${ }^{17}$

\section{Neurotrophic Growth Factors in the Auditory System}

Neurotrophin-3 (NT-3) is expressed in the cephalic spiral ganglia, while the Brain-Derived Neurotrophic Factor (BDNF) is mainly expressed in the basal spiral ganglion. $^{18}$ The regional concentrations of NT-3 and BDNF can thus partly determine tonotopic characteristics evolved from those of the spiral ganglion in the ear. ${ }^{19}$ The regulatory effects of NT-3 and BDNF on voltagedependent ion channels and synaptic protein composition in a spiral ganglion indicate that NT-3 and BDNF can separately activate different elements of Trk-dependent signaling pathways. ${ }^{19}$ During the initial period after birth, the mRNAs of NT-3 and BDNF genes are also expressed in internal or external hair cells, but only the NT-3 mRNA expression is maintained in adults' cochlea. ${ }^{20,21}$ Spiral ganglion neurons can also express TrkB and TrkC neurotrophic receptors and $\alpha-1$ receptor of glial cell-derived neurotrophic factor, showing that neurons of spiral ganglion respond to NT-3 and BDNF. ${ }^{22,23}$

\section{Transdifferentiation}

Transdifferentiation refers to the transformation of a fully differentiated cell into another one without the involvement of proliferative intermediate cell in this process. Transdifferentiation never occurs naturally neither does it occur at base levels, ${ }^{24}$ but this process needs increased expression of the selected transcription factor. Although mammals' neuronal cells never self-rebuild after birth, increase in the expression of some markers and the inhibition of signaling pathways may induce the regeneration of AN cells through the transdifferentiation process. ${ }^{25,26}$ Therefore, transdifferentiation is assumed as a useful method for the regeneration of ANs. Few factors have also been manipulated so far to generate ANs, and the regeneration of AN has been inefficient. Therefore, it is necessary to examine a more efficient combination of factors to achieve the regeneration of ANs for clinical applications. 


\section{MiRNA-I83 Family in the Auditory System}

In vertebrates, the miRNA-183 family is often expressed in sensory organs and the expression of this family in the inner ear is limited to hair cells and the spiral ganglion of neurons. Previous studies in this area have highlighted the importance of this family in the development and maintenance of the auditory system. ${ }^{27-29}$ Models from the miRNA-183 family in sensory neural tissues have also indicated the significance of this family in cellular protection of neurotransmitters, with additional roles in evolution, patterning, and synaptogenesis. These observations, along with controlled studies in the knockdown model of this family using the spongetransgenic technique, ${ }^{30}$ and the knockout of this family through gene trapping have correspondingly demonstrated that the removal of this family leads to the vulnerability of sensory and neural stimuli. The defect has been thus observed in the knocked-out mice of the miRNA-183 family using gene trapping, ${ }^{31}$ and mice with mutant miRNA- $96 .{ }^{32}$ The defects in synaptogenesis may also cause HL in knockout models of the family.

\section{Materials and Methods}

hBMSCs were purchased from Cell Therapy Center of Royan Institute (Tehran, Iran), and then cultured in the Dulbecco's modified Eagle's medium (DMEM) containing 15\% fetal bovine serum (FBS) and 1\% streptomycin and penicillin.

\section{Generation of Neurospheres of hBM-MSCs}

For the transformation of hBM-MSCs into neurospheres, the given cells were separated from flask after passage 4 in DMEM using the trypsin enzyme and were then centrifuged at $1500 \mathrm{rpm}$ for 5 minutes. The cellular deposition with a neurosphere differentiation medium containing DMEM/ F12 with basic fibroblast growth factor (bFGF) $20 \mathrm{ng} / \mathrm{mL}$ and EGF $10 \mathrm{ng} / \mathrm{mL}$, was subsequently suspended and transferred in non-treated 6-well tissue culture plates. After about an hour, the cells began to accumulate around and cellular assemblies were created. After culturing, cell masses were found in the culture media. The cell masses were then placed in the same culture medium for up to 3 days. The real-time Polymerase Chain Reaction (Real-time PCR) was also used for the confirmation of neurospheres. The sex determining region of Y-box 2 (SOX2) and nestin as markers were subsequently evaluated using this method. Moreover, their morphology was examined via an inverted microscope.

\section{Differentiation of Neurospheres into ANs}

The neurospheres were transferred from the non-treated 6 -well tissue culture plates into a 6-well plate coated with fibronectin and a differentiation medium was then added to them. The differentiation medium was used for differentiating the neurospheres into ANs of the DMEM/F12 medium including bFGF, N2, B27, BDNF, and NT-3. The cells were also exposed to treatments with BDNF and NT-3 for 5 days and were later on treated with bFGF and NT-3 for 6 days. The compositions and concentrations of the differentiation media for the ANs are listed in Table 1.

At the end of the 14th day, the cells were trypsinized, followed by RNA extraction, c-DNA synthesis, and realtime PCR for nestin, Ngn1, SOX2, tubulin, MAP2, and GATA3 genes. It should be noted that this stage was repeated for 3 times and the control group was used for each replication. In the course of cell differentiation, the morphology of the cells was examined through an inverted microscope.

\section{Transfection of hBM-MSCs Using MiRNA- 96, - I82, -183 and Scramble}

The day before the transfection, 150,000 cells were cultured in each 6-well cell plate. The next day, the medium was removed from the cells and $1.5 \mathrm{~mL}$ of the DMEM without serum and antibiotics were added to each of the wells. Solutions of miRNA-96, $-182,-183$ and negative

Table I Compositions and Concentrations of Constituents and Time for Differentiation into Neurospheres and ANs

\begin{tabular}{|l|l|l|l|l|l|}
\hline Neurosphere Medium & Time & First Differentiation Medium & Time & Second Differentiation Medium & Time \\
\hline DMEM/FI2 & 3 days & DMEM/FI2 & 5 days & DMEM/FI2 \\
bFGF $20 \mathrm{ng} / \mathrm{mL}$ & & NT-3 $30 \mathrm{ng} / \mathrm{mL}$ & & BDNF I0 ng/mL \\
EGF $10 \mathrm{ng} / \mathrm{mL}$ & & bFGF $20 \mathrm{ng} / \mathrm{mL}$ & & NT-3 $30 \mathrm{ng} / \mathrm{mL}$ \\
Antibiotic-antimycotic I\% & & B27 $2 \%$ & & B27 $2 \%$ \\
& & N2 $1 \%$ & N2 I\% \\
& & Antibiotic-antimycotic I\% & & Antibiotic-antimycotic I\% \\
\hline
\end{tabular}


control (ie, scramble) were also prepared at $50 \mathrm{nM}$ concentrations separately. The miRNA and Lipofectamine were then mixed in the ratio of 3:1 and were allowed to form complexes. Subsequently, the complex was slowly added to each of the wells. After $4 \mathrm{~h}$ of transfection, the medium was removed from the cells and the medium with antibiotics and fetal bovine serum (FBS) 10\% was added to each of the wells. After 24 and $48 \mathrm{~h}$ of transfection, the medium was removed and washed several times with Phosphate Buffered Saline (PBS), and ultimately RNA was extracted from the transfected cells.

\section{Real-Time PCR for Detection of MiRNA- 96, - 182, - 183 Expressions}

The accuracy of miRNA transfection in hBM-MSCs was examined using the real-time PCR. Total RNA was also isolated from cultured cells via Invitrogen ${ }^{\mathrm{TM}}$ TRIzol $^{\mathrm{TM}}$ Reagent (Ambion), according to the manufacturer's instructions. It should be noted that real-time miRNA assay has two steps: stem-loop real-time reaction and realtime PCR detection. Stem-loop real-time primers bind to the $3^{\prime}$ end of miRNA molecules and are transcribed with Reverse Transcriptase (RT). The extracted RNA was thus reverse-transcribed in the presence of a poly-A polymerase with an oligo-dT adaptor. Real-time PCR was then performed via SYBR ${ }^{\circledR}$ Green (Takara, Shiga, Japan) detection with a forward primer for miRNA-96, $-182,-183$; mature miRNA sequence, and a universal adaptor reverse primer. Real-time PCR was also completed using the Rotor-Gene $\mathrm{Q}$ (Qiagen, USA) with the following thermal cycling profile: $95^{\circ} \mathrm{C}$ for $2 \mathrm{~min}$, followed by 40 cycles of amplification $\left(95^{\circ} \mathrm{C}\right.$ for $5 \mathrm{~s}, 60^{\circ} \mathrm{C}$ for $\left.30 \mathrm{~s}\right)$. To normalize the miRNA content, the snord was the internal control. The relative expression values of coding genes and mature miRNAs of interest were ultimately calculated using the $2^{-\Delta \Delta \mathrm{Ct}}$ method.

\section{Use of Real-Time PCR to Evaluate Expression of Genes}

To isolate the total RNA from the cells (treated with growth factors and transfected with miRNA and control cells), the Invitrogen ${ }^{\mathrm{TM}}$ TRIzol $^{\mathrm{TM}}$ Reagent (Ambion) was used based on the manufacturer's protocol. The RNA samples were also measured through a spectrophotometer (NanoDrop ${ }^{\circledR}$, Thermo Fisher Scientific) and were evaluated both qualitatively and quantitatively. A total of $2 \mu \mathrm{g}$ of RNA was then employed to synthesize cDNA using a kit (Thermo
Scientific-K1622) and a device (Corbett). The thermal conditions for real-time PCR included a denaturation of $3 \mathrm{~min}$ at $95^{\circ} \mathrm{C}$, and then 40 cycles at $95^{\circ} \mathrm{C}$ for 15 seconds and $72^{\circ} \mathrm{C}$ for 25 seconds. The primers used for each of the genes in this study are shown in Table 2. The relative expression level of mRNAs was also calculated via $2^{-\Delta \Delta C t}$ method. Also, $18 S$ was further used as a reference gene in the growth factor-treated cells and from Glyceraldehyde 3-Phosphate Dehydrogenase Human (GAPDH) as a reference gene in miRNA transfected cells. The Kruskal-Wallis test was correspondingly utilized to compare the expression of genes in three groups, and the Mann-Whitney $U$-test was employed to determine the level of significance in both groups. The p-value of less than 0.05 was considered as significant.

After the transfection of miRNA-96, $-182,-183$; the expression level of $\mathrm{Ngn} 1$ and $\mathrm{SOX} 2$ genes were firstly evaluated. In case the expression of these genes were significant, the expression of nestin, tubulin, MAP2, GATA3, and peripherin genes were then evaluated.

\section{Results}

This experimental study tries to investigate constructing ANs from hBMSCs, with the primary objective of achieving neurosphere. To this end, as shown in Table 1, the cultivation of hBMSCs was performed under conditions of neuralization. EGF and bFGF treatment resulted in

Table 2 Primers Used in Real-Time PCR for mRNAs

\begin{tabular}{|l|l|}
\hline Name & Sequence \\
\hline NgnI & $\begin{array}{l}\text { F- AAACGAGCATGAAAATTCGGT } \\
\text { R- ATGAAGCCCACTCCTTGTCT }\end{array}$ \\
\hline GATA3 & $\begin{array}{l}\text { F- TGTCAGACCACCACAACCACAC } \\
\text { R- CTGGATGCCTTCCTTCTTCATAGT }\end{array}$ \\
\hline Peripherin & $\begin{array}{l}\text { F- CACGCTCCTCATTTGGCTCTTC } \\
\text { R- GGCTCTCGCTCTCAGATTCCTC }\end{array}$ \\
\hline I8S & $\begin{array}{l}\text { F- GAGTCCACTGGCGTCTTCAC } \\
\text { R- ATGACGAACATGGGGGCATC }\end{array}$ \\
\hline MAP2 & $\begin{array}{l}\text { F- GTAACCCGTTGAACCCCATTCGT } \\
\text { R-ACCATCCAATCGGTAGTAGCGACG }\end{array}$ \\
\hline Tubulin & $\begin{array}{l}\text { F- CGGAGTAACCAAGAGCCCAGAAAAG } \\
\text { R- GAGTGCCTGGTGTGCGTGAAGA }\end{array}$ \\
\hline Nestin & $\begin{array}{l}\text { F- CCATGGACAGTGTCCGCTCAGG } \\
\text { R- ACTCCTTCCGCACCACATCCAG }\end{array}$ \\
\hline
\end{tabular}




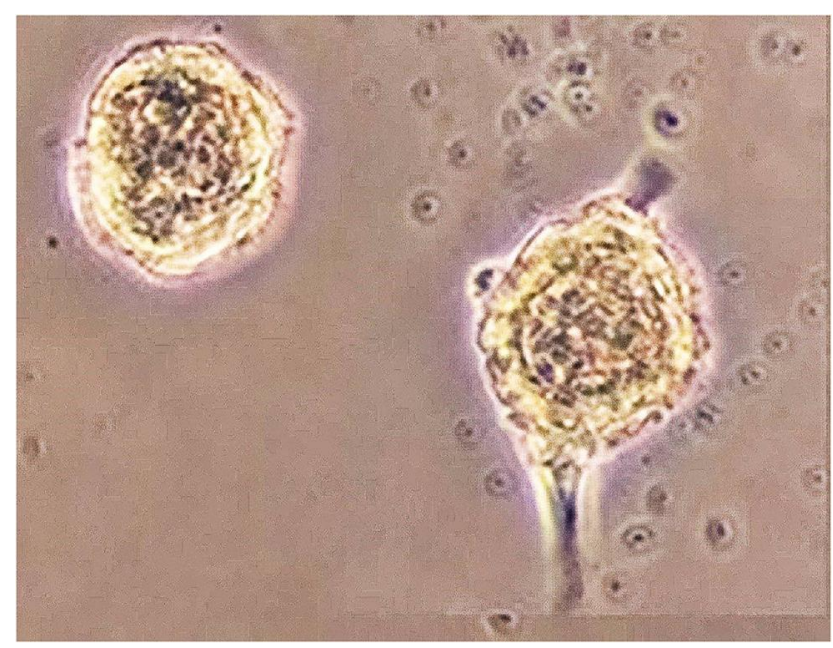

Figure I Generation neurospheres from hBM-MSCs. Morphology of neurospheres derived from hBM-MSCs. This morphology shows neurospheres three days after differentiation (Visualized by inverted microscope magnification 10x).

neurospheres (Figure 1) derived from hBMSCs. Nestin and Sox-2 expression changes were analyzed to understand the treatment effects. In neural stem/progenitor cells, an intermediate filament protein is encoded by Nestin that plays a role in MSC differentiation in to neural precursor lineages. The expression of Sox-2 transcription factor, belonging to family SRY-related HMG box, occurs in otic neural progenitors and acts as a factor in neural commitment and self-renewal. Regarding the real-time PCR findings, the levels of Sox-2 and Nestin mRNA were enhanced in hBMSC cultures under previously mentioned conditions. The supplementation of neurotrophic factors continued for another eleven days to further accelerate the neurosphere maturation. A medium containing NT-3 and bFGF was used to culture the neurospheres for supporting the auditory sensory neuron survival. Then, the cultures were exposed to BDNF for regulating the ANs differentiation sequentially, see Figure 2, so that it was possible to monitor the elevation in the transcriptional levels of Sox-2 and Ngn-1 genes that are expressed commonly in ANs during development phase. The undifferentiated morphology prior to dissociation can be observed in the cells in (Figure 2A), whereas spindle-shaped hBMSCs took neuron-like shape after their ANs induction following exposure to neural induction medium for 11days (Figure 2B-E).

The results of the morphological changes of hBMMSCs cells after being treated with growth factors and miRNA transfection were as follows (Figures 1-3).

\section{Expression of Neurospheres and Differentiation Genes}

The expression in hBMSCs transfected by miRNA-96, -182, -183 and scramble was evaluated after 24 and 48 hours by real-time PCR method. According to the findings, there was an increase in the miRNA-96, miRNA-182 and miRNA-183 expression level in the cells transfected with miRNA-96,

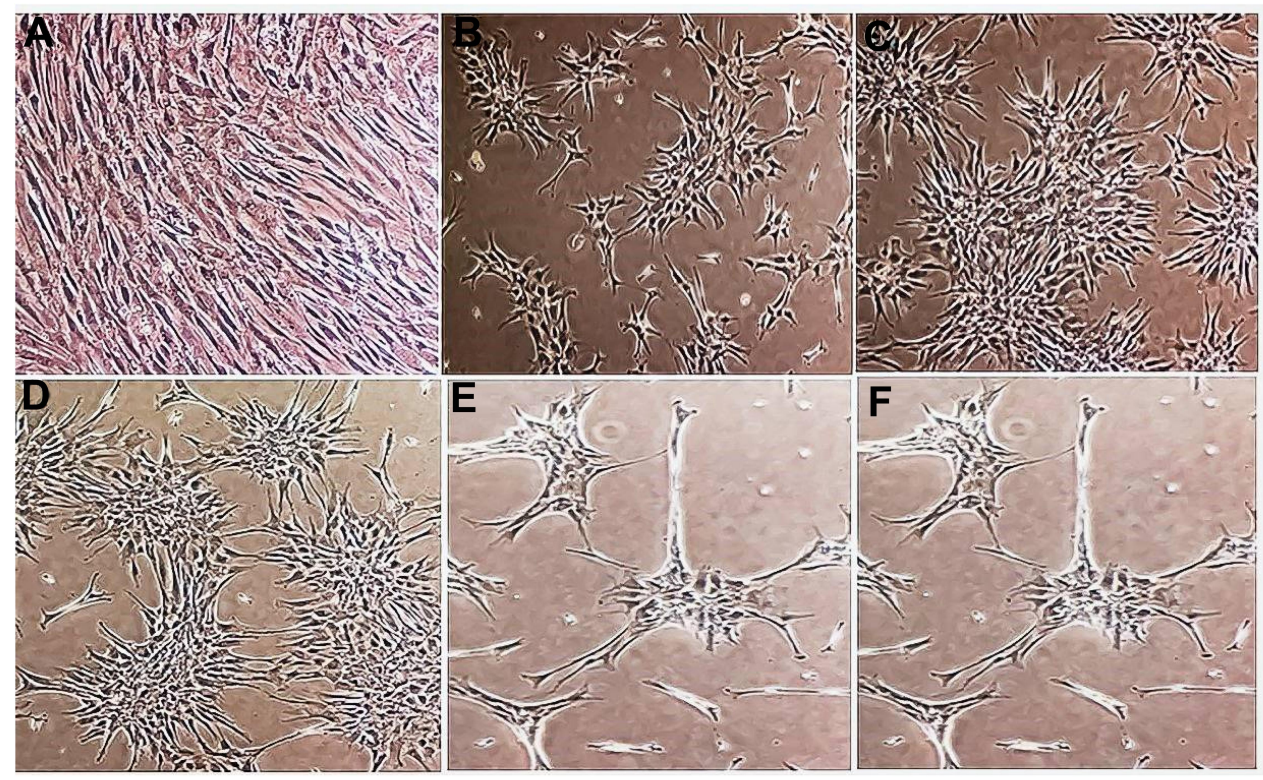

Figure 2 Changes in hBM-MSCs morphology after growth factor treatment. (A) Morphology of hBM-MSCs at 4× magnifications in basic growth medium (DMEM). (B-D) Morphology of hBM-MSCs at $4 \times$ magnifications in growth factor-enriched medium. (E and F) Morphology of hBM-MSCs at I0x magnifications in growth factor-enriched medium (Visualized by an inverted microscope). 


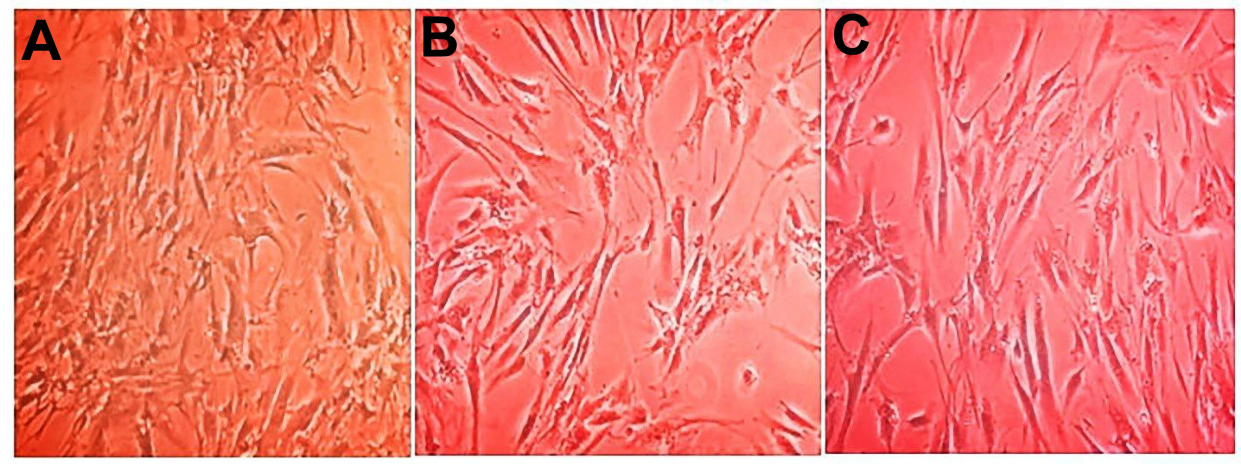

Figure 3 Changes in hBM-MSCs morphology after transfection scramble and miRNA. (A) hBM-MSCs after scramble transfection (B) hBM-MSCs $24 \mathrm{~h}$ post-transfection with miRNA-182 mimic (C) hBM-MSCs 48 h post-transfection with miRNA-182 mimic (visualized by inverted microscope magnification 4x) Changes in expressions of nestin, tubulin, MAP2, Ngn I, peripherin, GATA3, and SOX2 genes in hBM-MSCs after treatments with growth factors and transfection with miRNA.

miRNA-182 and miRNA-183 when comparing to the cells transfected with scramble in both time points. The miRNA182 transfection impacts on neurospheres and differentiation genes, including SOX2, GATA3, peripherin, Ngn1, MAP2, tubulin and nestin, was evaluated after 24 and 48 hours using real-time PCR method (Figures 4 and 5). After 24 hours, there was a significant upregulation in $\mathrm{Ngn1}$, peripherin and $S O X 2$ expression in comparison with the control. In treatment with growth factors $N g n 1$ and $S O X 2$ markers displayed a significant increase, but tubulin, MAP2, and GATA3 markers were not statistically significant (Figures 6 and 7). Based on the real-time PCR findings on the miR96- and miR183- transfected cells, no changes were found in GATA3, peripherin, Ngn1, MAP2, tubulin and nestin mRNAs after 24 and 48 hours (Figures 8 and 9). Additionally, a significant reduction was observed in the expression of SOX2 gene after 48 hours in comparison with the control (Figure 9).

\section{Discussion}

The neurospheres derived from hBM-MSCs were treated in this study using bFGF, NT-3, and BDNF growth factors as well as $\mathrm{N} 2$ and B27 supplements in order to evaluate the differentiation of hBM-MSCs into ANs. It should be noted that $\mathrm{N} 2$ and B27 supplements were used for nerve

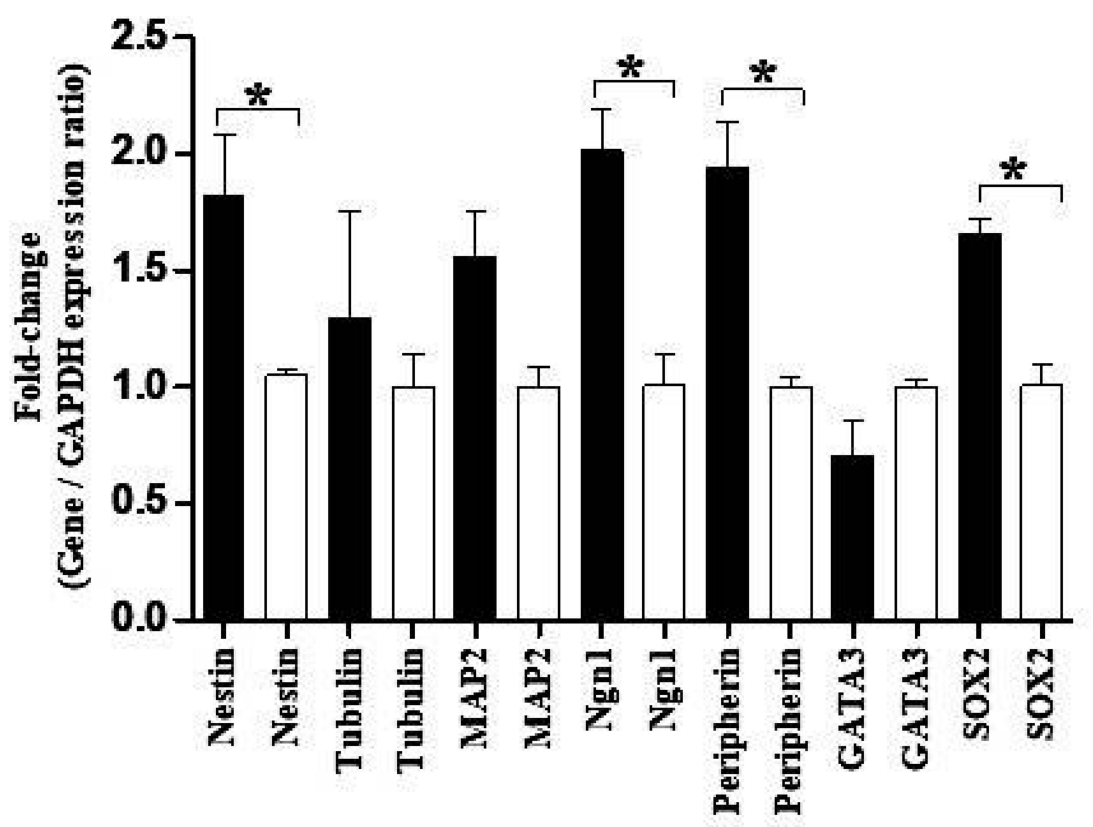

Transfection miR-182 24 h Transfection scramble $24 \mathrm{~h}$

Figure 4 Evaluation expression of nestin, tubulin, MAP2, Ngn I, peripherin, GATA3, and SOX2 in hBM-MSCs transfected with miR-I82 mimic and scramble. Real-time PCR showed significant up-regulation of nestin, Ngn I, peripherin, SOX2 mRNAs in transfected cells after 24 h. The data were normalized to GAPDH and represent mean \pm standard deviation (SD) of three independent experiments with $n=3$. Asterisks showed significance expression rate: $* P<0.05$. 


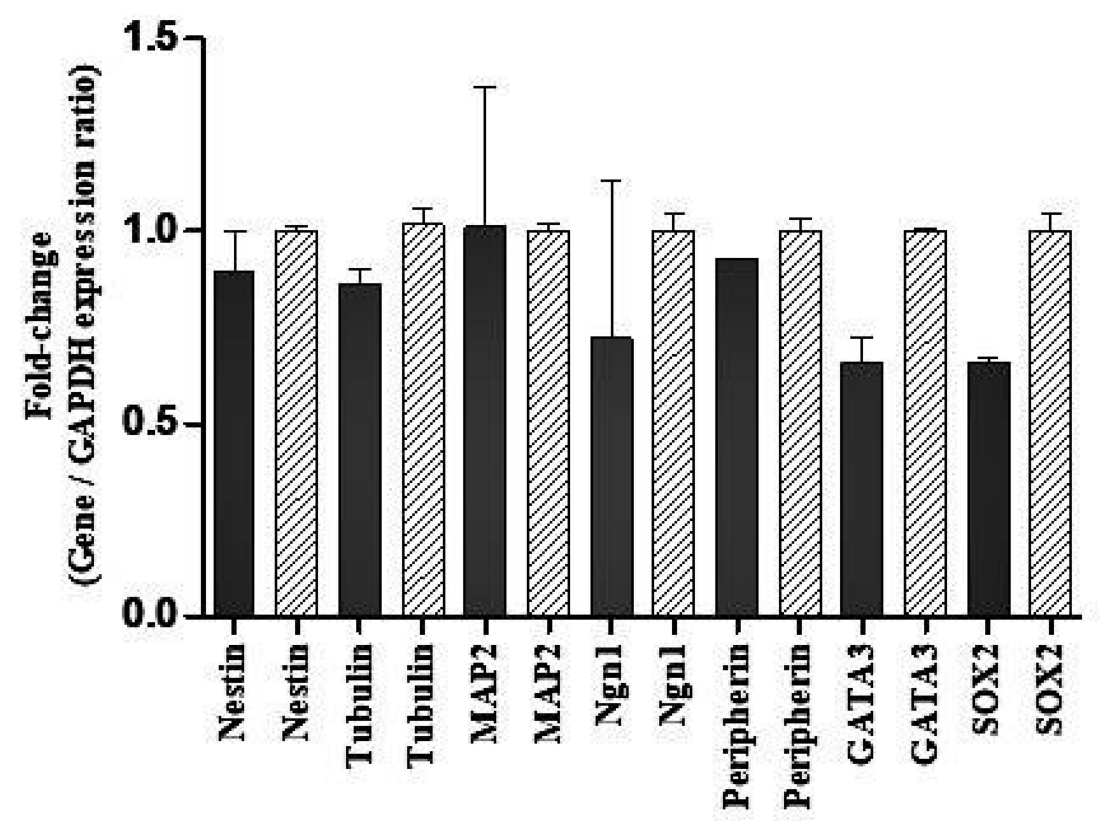

Figure 5 Evaluation expression of nestin, tubulin, MAP2, Ngnl, peripherin, GATA3, and SOX2 in hBM-MSCs transfected with miR-I82 mimic and scramble. Real-time PCR revealed no change of nestin, tubulin, MAP2, Ngnl, peripherin, GATA3, and SOX2 mRNAs in transfected cells after $48 \mathrm{~h}$. The data were normalized to GAPDH and denote mean $\pm \mathrm{SD}$ of three independent experiments with $\mathrm{n}=3$.

A

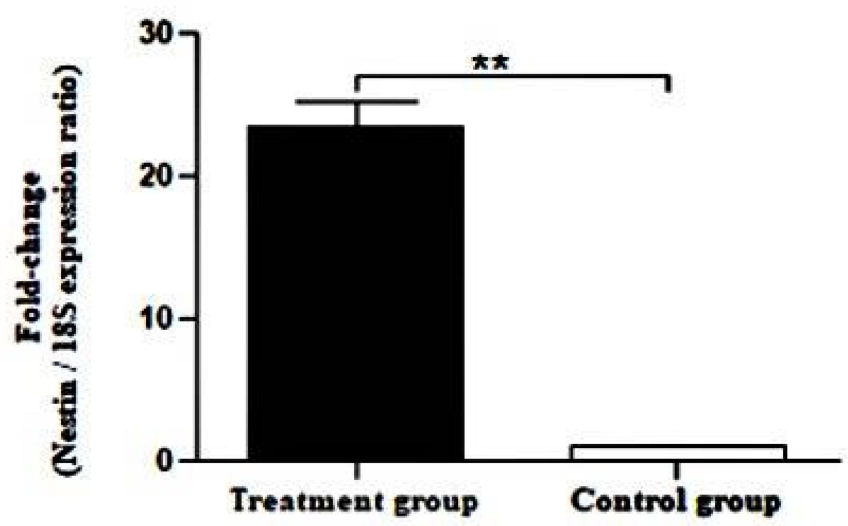

B

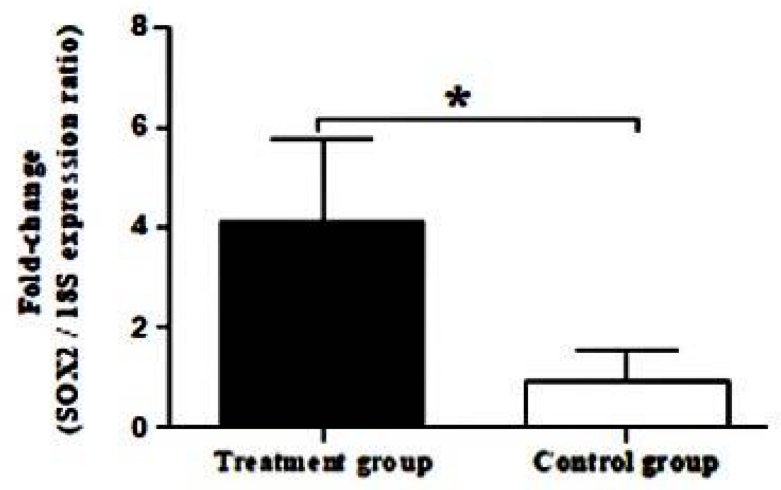

Figure 6 Real-time PCR for expression of nestin and SOX2 in neurospheres. (A) Evaluation expression of nestin in hBM-MSCs after growth factor treatment. (B) Evaluation expression of SOX2 in hBM-MSCs after growth factor treatment. Real-time PCR data indicate increased messenger RNA (mRNA) expression of nestin and SOX2 genes. The data were normalized to $18 \mathrm{~S}$. All data also represent mean $\pm \mathrm{SD}$ of three independent experiments with $\mathrm{n}=3$. Asterisks showed significance expression rate: $* \mathrm{P}<0.05$ $* * \mathrm{P}<0.001$.

differentiation once it was performed under non-serum conditions. $^{33,34}$ bFGF accelerates proliferation of neurocotodromes and acts as a neurotropic agent for survival and neural differentiation. In addition, fibroblastic growth factors are essential for the induction of otic placode. Studies in this area have revealed that neurotrophins, particularly NT-3, and a neurotrophic factor derived from the brain ie, BDNF, are vital for maintaining peripheral fibers and spiral ganglion neurons in adult cochlea. ${ }^{35-37}$ In this study, the protocols used for embryonic stem cells and growth factors such as BDNF and NT-3, which contribute to normal development of the ears; were combined. In order to evaluate the differentiation into ANs; not only morphological features, but also an evaluation based on real-time PCR was used. In order to assess the differentiation via real-time PCR; the expression levels of Ngn1, nestin, SOX2, tubulin, MAP2, and GATA3 markers were also measured. As mentioned in the results section, almost all of the specific markers of the AN were studied using real-time PCR. The Ngn1 and SOX2 markers also showed 


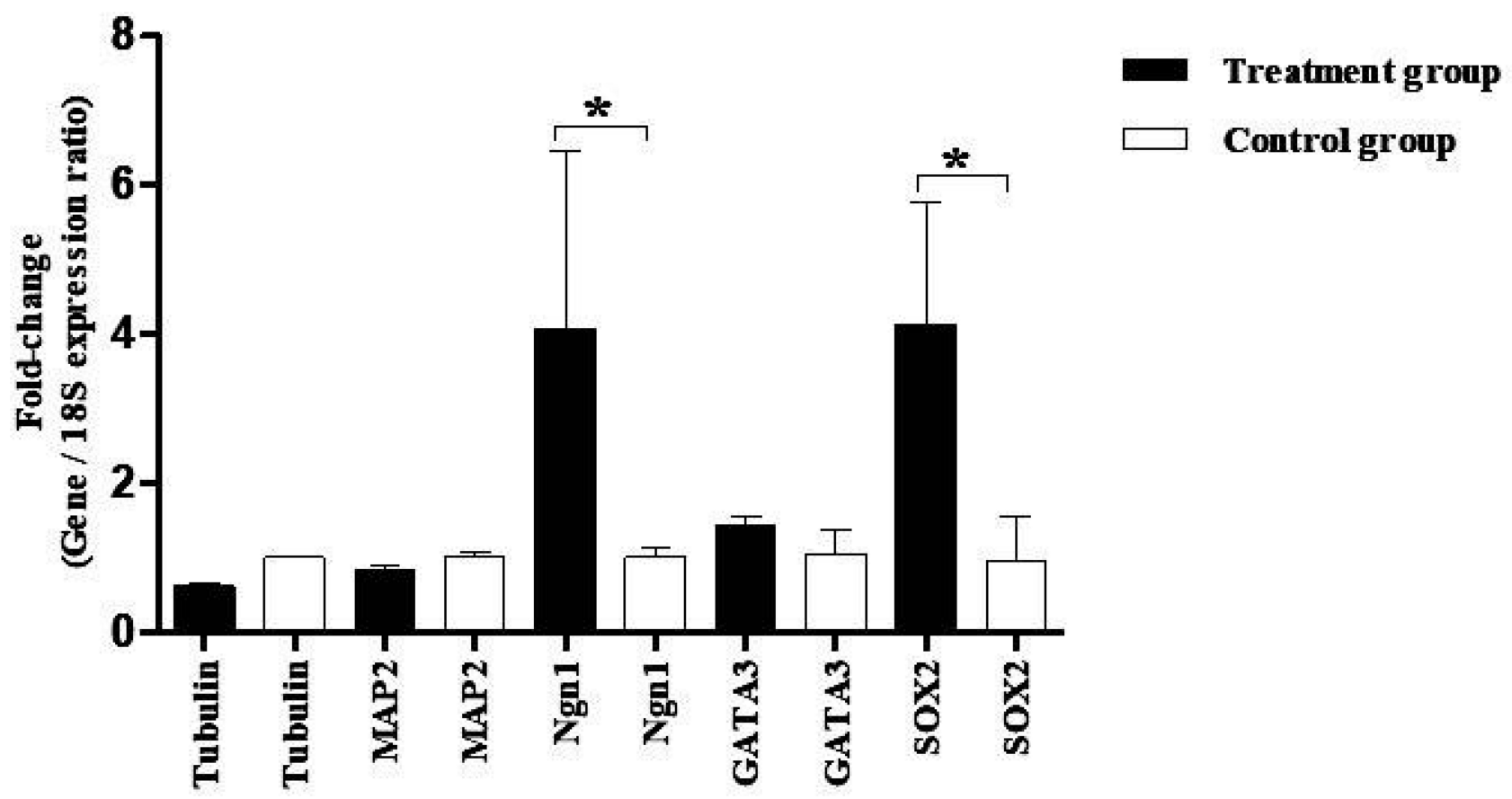

Figure 7 Evaluation expression of tubulin, MAP2, Ngnl, GATA3, and SOX2 in hBM-MSCs after growth factor treatment. Real-time PCR data denote increased mRNA expression of $\mathrm{Ngnl}$ and SOX2 genes. The data were normalized to I8S. All data also represent mean \pm SD of three independent experiments with $\mathrm{n}=3$. Asterisks showed significance expression rate: $* \mathrm{P}<0.05$.

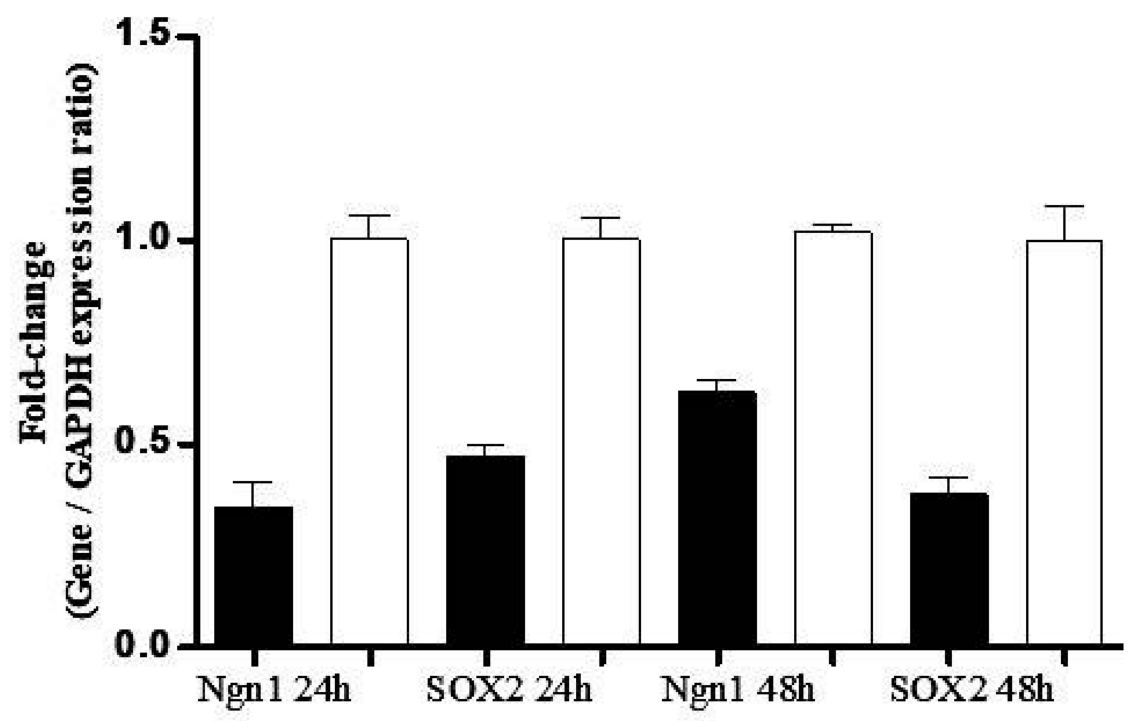

Figure 8 Evaluation of $\mathrm{Ngnl}$ and SOX2 in hBM-MSCs transfected with miRNA-96 mimic and scramble. Real-time PCR showed no change in Ngnl, SOX2 mRNAs in the transfected cells after $24 \mathrm{~h}$ and $48 \mathrm{~h}$. The data were normalized to GAPDH. All data represent mean \pm SD of three independent experiments with $\mathrm{n}=3$.

a significant increase, but tubulin, MAP2, and GATA3 markers were not statistically significant. The reason for the insignificant increase in GATA3 expression in this study was that since the GATA3 marker is a final-stage differentiation factor of $\mathrm{AN}$, cells may not still have entered the final phase of neuronal differentiation at the quantitative measurements at mRNA level of these genes.
One of the important markers revealed by the increased expression was $\mathrm{Ngn1}$. The $\mathrm{Ngnl}$ expression is essential for the generation of spiral ganglion neurons in the inner ear. ${ }^{38}$ Another important marker shown by the increased expression was $S O X 2$, which is among the first definitive markers of the neural pre-sensory region in the inner ear. Moreover, SOX2 plays a leading role in maintaining a set of potent 


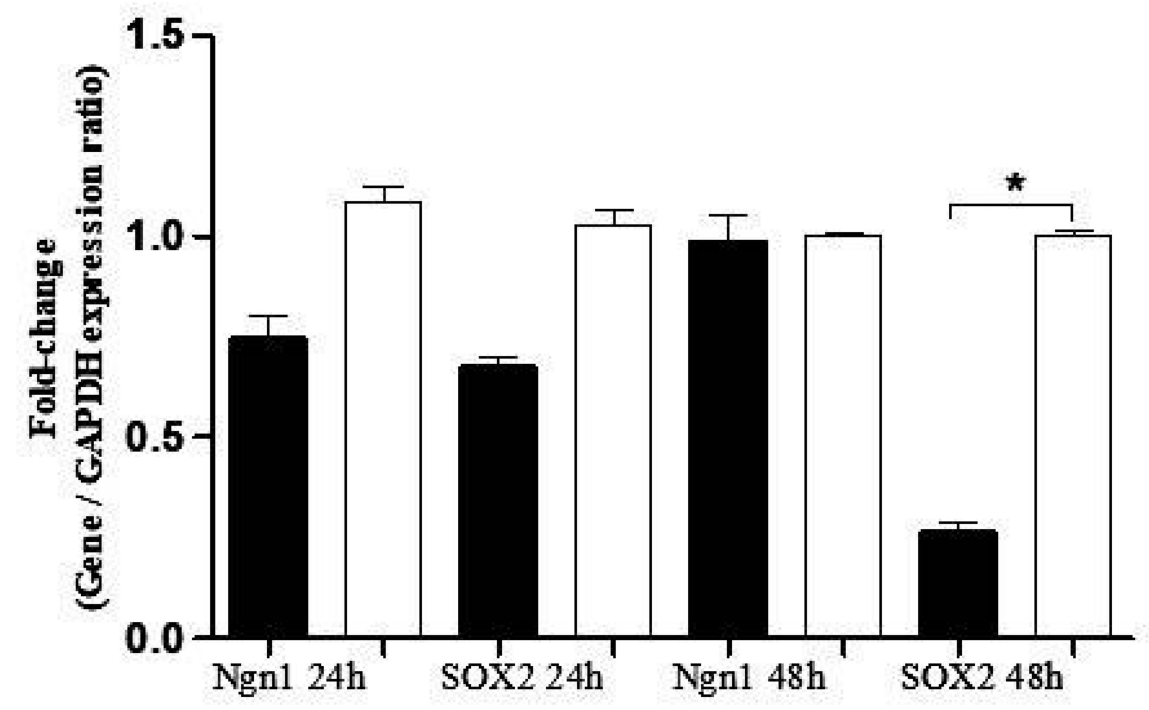

Transfection miR-183

Transfection scramble

Figure 9 Evaluation expression of NgnI and SOX2 in hBM-MSCs transfected with miRNA-I83 mimic and scramble. Real-time PCR showed no change in Ngn I and SOX2 mRNAs in the transfected cells after $24 \mathrm{~h}$ and $48 \mathrm{~h}$. The data were normalized to GAPDH. All data denote mean \pm SD of three independent experiments with $\mathrm{n}=3$. Asterisks showed significance expression rate: ${ }^{*} \mathrm{P}<0.05$.

progenitors and controlling differentiation of neurons and sensory epithelial cells. The SOX2 is also essential for the formation of sensory cells and spiral ganglia. ${ }^{39}$ Therefore, this protocol may not be considered optimal with regards to the results of the treatments used in this study for generating ANs, which includes BDNF, NT-3, and bFGF. Direct injection of the neurotrophic peptide factors of BDNF and NT-3 in the cochlea, whether alone or in combination with other factors, also improves the survival of spiral ganglion after degeneration of aminoglycoside or sound-induced hair cells. ${ }^{40,41}$ Neurotrophic factors not only prevent secondary degeneration of spiral ganglion, but also improve the development of spiral ganglion neurons. ${ }^{41-43}$ The end of BDNF injections also helps in degenerating spiral ganglia faster. ${ }^{41,44}$ The miRNA-96, -182 , and -183 with a concentration of $50 \mathrm{nM}$ were thus transfected into hBM-MSCs and the results showed that an increased expression of miRNA-182, rather than miRNA96 and 183 had boosted the expression of some AN marker. The genes that changed after miRNA-182 transfection also had a major role in the differentiation of the AN. The findings revealed that the expression of miRNA182 in the family of miRNA-183 could increase the expression of some AN marker (ie, Ngn1, SOX2, peripherin, and nestin) in vitro. These findings can definitely contribute to future studies dealing with molecular pathways involved in differentiation and also the survival of AN cells. The miRNAs regulate stem cell fate through targeting specific pluripotency factors or differentiation pathways. ${ }^{45}$ According to the results of this study, it can be stated that miR-182 increases the expression of SOX2, Ngn1, tubulin, and peripherin genes; thereby helping in differentiating hBM-MSCs into ANs. Accordingly, there is a need for miRNAs during the early stages of the development of the ears and for the differentiation of the hair cells. Since hundreds of transcripts are simultaneously regulated by miRNAs, they can be regarded as potential agents for the regeneration of ANs in animal models. ${ }^{46}$ The identification of the target genes of the miRNA-182 and the pathways affected by them are thus expected to provide important information about the development and maintenance of the inner ear. They may also provide drug targets to accelerate and develop a protection of sensory nerve cells.

\section{Conclusion}

With regards to their small size, fast synthesis, nuclease resistance, and half-life, as well as long-term biological activity; miRNA is probably a good substitute for growth factors used in differentiating into different cell types. Growth factors can also increase the expression of Ngn1 and $S O X 2$ genes, but miRNA can boost the expression of more specific genes (ie, Ngn1, SOX2, peripherin, and nestin). The miRNA-182 transfection also augments the expression of target genes after $24 \mathrm{~h}$ and this change in gene expression may depend on the dose of miRNA- 182 . Transdifferentiation of stem cells into ANs, which does not occur under normal conditions, may be thus facilitated 
by miRNAs, especially miR-182, or via a combination of miRNA and growth factors.

\section{Data Sharing Statement}

All data used to support the findings of this study are included within the article.

\section{Ethics and Consent}

This article does not contain any studies with human participants or animals performed by any of the authors.

\section{Author Contributions}

All authors contributed towards data analysis, drafting and critically revising the paper, gave final approval of the version to be published, and agreed to be accountable for all aspects of the work.

\section{Disclosure}

The authors report no conflicts of interest in this work.

\section{References}

1. Organization WH. WHO Global Estimates on Prevalence of Hearing Loss; 2012.

2. Mehri-Ghahfarrokhi A, Hashemzadeh-Chaleshtori M, Shojaeian A, Mahmoudian Sani MR. Studying gap junction beta 2-related deafness in Iranian population. Otorinolaringologia. 2017;67(3):89-95. doi:10.23736/S0392-6621.17.02115-4

3. Mahmoudian Sani MR, Mehri-Ghahfarrokhi A, Ahmadi H, et al. Study of common mitochondrial mutations in patients with nonsyndromic hearing loss. Otorinolaringologia. 2017;67(2):61-67. doi:10.23736/S0392.6621.17.02103-8

4. Zeng F-G, Rebscher S, Harrison W, Sun X, Feng H. Cochlear implants: system design, integration, and evaluation. IEEE Rev Biomed Eng. 2008;1:115-142. doi:10.1109/RBME.2008.2008250

5. Ahmadi H, Sani HM, Farnoosh G, Sani MRM. Comparative study of speech and language development in children with normal hearing and cochlear implant in Iran. Indian J Otol. 2017;23(3):135-140. doi:10.4103/indianjotol.INDIANJOTOL_51_17

6. Warchol ME. Sensory regeneration in the vertebrate inner ear: differences at the levels of cells and species. Hear Res. 2011;273(12):72-79. doi:10.1016/j.heares.2010.05.004

7. Oshima K, Grimm CM, Corrales CE, et al. Differential distribution of stem cells in the auditory and vestibular organs of the inner ear. $J$ Assoc Res Otolaryngol. 2007;8(1):18-31. doi:10.1007/s10162-0060058-3

8. Conde de Felipe M, Feijoo Redondo A, García-Sancho J, Schimmang T, Durán M. Cell- and gene-therapy approaches to inner ear repair. Histol Histopathol. 2011;26(7):923-940. doi:10. 14670/HH-26.923

9. Mahmoudian-Sani M-R, Hashemzadeh-Chaleshtori M, Jami M-S, Saidijam M. In vitro differentiation of human bone marrow mesenchymal stem cells to hair cells using growth factors. Int Tinnitus J. 2017;21(2):179-184. doi:10.5935/0946-5448.20170030

10. Erdö F, Bührle C, Blunk J, et al. Host-dependent tumorigenesis of embryonic stem cell transplantation in experimental stroke. J Cereb Blood Flow Metab. 2003;23(7):780-785. doi:10.1097/01.WCB.00 00071886.63724.FB
11. Sell S. Stem cell origin of cancer and differentiation therapy. Crit Rev Oncol Hematol. 2004;51(1):1-28. doi:10.1016/j.critrevonc.2004. 04.007

12. Mahmoudian Sani MR, Mehri-Ghahfarrokhi A, HashemzadehChaleshtori M, Saidijam M, Jami M-S. Comparison of three types of mesenchymal stem cells (bone marrow, adipose tissue, and umbilical cord-derived) as potential sources for inner ear regeneration. Int Tinnitus J. 2017;21(2). doi:10.5935/0946-5448.20170023

13. Kondo T, Johnson SA, Yoder MC, Romand R, Hashino E. Sonic hedgehog and retinoic acid synergistically promote sensory fate specification from bone marrow-derived pluripotent stem cells. Proc Natl Acad Sci. 2005;102(13):4789-4794. doi:10.1073/pnas.0408239102

14. Sekiya T, Kojima K, Matsumoto M, Ito J. Replacement of diseased auditory neurons by cell transplantation. Front Biosci. 2008;13:2165-2176. doi:10.2741/2832

15. Rubel EW, Fritzsch B. Auditory system development: primary auditory neurons and their targets. Annu Rev Neurosci. 2002;25 (1):51-101. doi:10.1146/annurev.neuro.25.112701.142849

16. Starr A, Picton TW, Sininger Y, Hood LJ, Berlin CI. Auditory neuropathy. Brain. 1996;119(3):741-753. doi:10.1093/brain/119.3.741

17. Chen W, Jongkamonwiwat N, Abbas L, et al. Restoration of auditory evoked responses by human ES-cell-derived otic progenitors. Nature. 2012;490(7419):278-282. doi:10.1038/nature11415

18. Schimmang T, Tan J, Müller M, et al. Lack of Bdnf and TrkB signalling in the postnatal cochlea leads to a spatial reshaping of innervation along the tonotopic axis and hearing loss. Development. 2003;130(19):4741-4750. doi:10.1242/dev.00676

19. Flores-Otero J, Xue HZ, Davis RL. Reciprocal regulation of presynaptic and postsynaptic proteins in bipolar spiral ganglion neurons by neurotrophins. J Neurosci. 2007;27(51):14023-14034. doi:10.1523/ JNEUROSCI.3219-07.2007

20. Ernfors P, Lee K-F, Jaenisch R. Mice lacking brain-derived neurotrophic factor develop with sensory deficits. Nature. 1994;368 (6467):147-150. doi:10.1038/368147a0

21. Ylikoski J, Pirvola U, Virkkala J, et al. Guinea pig auditory neurons are protected by glial cell line-derived growth factor from degeneration after noise trauma. Hear Res. 1998;124(1-2):17-26. doi:10.1016/S0378-5955(98)00095

22. Fariñas I, Jones KR, Tessarollo L, et al. Spatial shaping of cochlear innervation by temporally regulated neurotrophin expression. $J$ Neurosci. 2001;21(16):6170-6180. doi:10.1523/jneurosci.21-1606170.2001

23. Shepherd RK, Roberts LA, Paolini AG. Long-term sensorineural hearing loss induces functional changes in the rat auditory nerve. Eur $J$ Neurosci. 2004;20(11):3131-3140. doi:10.1111/j.14609568.2004.03809.x

24. Ladewig J, Koch P, Brüstle O. Leveling Waddington: the emergence of direct programming and the loss of cell fate hierarchies. Nat Rev Mol Cell Biol. 2013;14(4):225-236. doi:10.1038/nrm3543

25. Kawamoto K, Ishimoto S-I, Minoda R, Brough DE, Raphael Y. Math1 gene transfer generates new cochlear hair cells in mature guinea pigs in vivo. $J$ Neurosci. 2003;23(11):4395-4400. doi:10.1016/S1525-0016(16)41269-4

26. Mizutari K, Fujioka M, Hosoya M, et al. Notch inhibition induces cochlear hair cell regeneration and recovery of hearing after acoustic trauma. Neuron. 2013;77(1):58-69. doi:10.1016/j.neuron.2012.10.032

27. Hashemzadeh-Chaleshtori M, Saidijam M, Jami M-S, GhasemiDehkordi P. MicroRNA-183 family in inner ear: hair cell development and deafness. J Audiol Otol. 2016;20(3):131. doi:10.7874/ jao.2016.20.3.131

28. Mahmoudian-sani M-R, Mehri-Ghahfarrokhi A, Ahmadinejad F, Hashemzadeh-Chaleshtori M, Saidijam M, Jami M-S. MicroRNAs: effective elements in ear-related diseases and hearing loss. Eur Arch Otorhinolaryngol. 2017;274(6):2373-2380. doi:10.1007/s00405-0174470-6 
29. Mahmoodian-sani M-R, Mehri-Ghahfarrokhi A. The potential of miR-183 family expression in inner ear for regeneration, treatment, diagnosis and prognosis of hearing loss. J Otol. 2017;12(2):55-61. doi:10.1016/j.joto.2017.03.003

30. Zhu Q, Sun W, Okano K, et al. Sponge transgenic mouse model reveals important roles for the microRNA-183 (miR-183)/96/182 cluster in postmitotic photoreceptors of the retina. J Biol Chem. 2011;286(36):31749-31760. doi:10.1074/jbc.M111.259028

31. Lumayag S, Haldin $\mathrm{CE}$, Corbett $\mathrm{NJ}$, et al. Inactivation of the microRNA-183/96/182 cluster results in syndromic retinal degeneration. Proc Natl Acad Sci. 2013;110(6):E507-E516. doi:10.1073/pnas.1212655110

32. Kuhn S, Johnson SL, Furness DN, et al. miR-96 regulates the progression of differentiation in mammalian cochlear inner and outer hair cells. Proc Natl Acad Sci. 2011;108(6):2355-2360. doi:10.1073/ pnas. 1016646108

33. Heng BC, Lim LW, Wu W, Zhang C. An overview of protocols for the neural induction of dental and oral stem cells in vitro. Tissue Eng Part B Rev. 2016;22(3):220-250. doi:10.1089/ten.TEB.2015.0488

34. Páll O, Varga B, Collart-Dutilleul P-Y, Gergely C, Cuisinier FJG. Re:"An Overview of Protocols for the Neural Induction of Dental and Oral Stem Cells In Vitro" by Heng et al.(Tissue Eng Part B 2016; 22: 220-250). Tissue Eng Part B Rev. 2017;23(6):570-576. doi:10.1089/ ten.TEB.2016.0512

35. Ernfors P, Lee K-F, Kucera J, Jaenisch R. Lack of neurotrophin-3 leads to deficiencies in the peripheral nervous system and loss of limb proprioceptive afferents. Cell. 1994;77(4):503-512. doi:10.1016/ 0092-8674(94)90213-5

36. Fritzsch B, Silos-Santiago I, Bianchi LM, Farinas I. The role of neurotrophic factors in regulating the development of inner ear innervation. Trends Neurosci. 1997;20(4):159-164. doi:10.1016/ s0166-2236(96)01007-7

37. Agerman K, Hjerling-Leffler J, Blanchard MP, et al. BDNF gene replacement reveals multiple mechanisms for establishing neurotrophin specificity during sensory nervous system development. Development. 2003;130(8):1479-1491. doi:10.1242/dev.00378
38. Romand R, Varela-Nieto I. Development of Auditory and Vestibular Systems. Academic Press; 2014.

39. Kiernan AE, Pelling AL, Leung KK, et al. Sox2 is required for sensory organ development in the mammalian inner ear. Nature. 2005;434(7036):1031-1035. doi:10.1038/nature03487

40. Gillespie LN, Clark GM, Bartlett PF, Marzella PL. BDNF-induced survival of auditory neurons in vivo: cessation of treatment leads to accelerated loss of survival effects. J Neurosci Res. 2003;71 (6):785-790. doi:10.1002/jnr.10542

41. Wise AK, Richardson R, Hardman J, Clark G, O'Leary S. Resprouting and survival of guinea pig cochlear neurons in response to the administration of the neurotrophins brain-derived neurotrophic factor and neurotrophin-3. J Comp Neurol. 2005;487(2):147-165. doi:10.1002/cne.20563

42. Glueckert R, Bitsche M, Miller JM, et al. Deafferentiation-associated changes in afferent and efferent processes in the guinea pig cochlea and afferent regeneration with chronic intrascalar brain-derived neurotrophic factor and acidic fibroblast growth factor. J Comp Neurol. 2008;507(4):1602-1621. doi:10.1002/cne.21619

43. McGuinness SL, Shepherd RK. Exogenous BDNF rescues rat spiral ganglion neurons in vivo. Otol Neurotol. 2005;26(5):1064. doi:10.1097/01.mao.0000185063.20081.50

44. Yagi M, Kanzaki S, Kawamoto K, et al. Spiral ganglion neurons are protected from degeneration by GDNF gene therapy. J Assoc Res Otolaryngol. 2000;1(4):315. doi:10.1007/s101620010011

45. Li N, Long B, Han W, Yuan S, Wang K. microRNAs: important regulators of stem cells. Stem Cell Res Ther. 2017;8(1):110. doi:10.1186/s13287-017-0551-0

46. Wang X-R, Zhang X-M, Zhen J, Zhang P-X, Xu G, Jiang $H$. MicroRNA expression in the embryonic mouse inner ear. Neuroreport. 2010;21(9):611-617. doi:10.1097/WNR.0b013e328338 $864 \mathrm{~b}$
Stem Cells and Cloning: Advances and Applications

\section{Publish your work in this journal}

Stem Cells and Cloning: Advances and Applications is an international, peer-reviewed, open access journal. Areas of interest in established and emerging concepts in stem cell research include: Embryonic cell stems; Adult stem cells; Blastocysts; Cordblood stem cells; Stem cell transformation and culture; Therapeutic cloning; Umbilical cord blood and bone marrow cells; Laboratory,

\section{Dovepress}

animal and human therapeutic studies; Philosophical and ethical issues related to stem cell research. This journal is indexed on CAS. The manuscript management system is completely online and includes a very quick and fair peer-review system, which is al easy to use. Visit http://www.dovepress.com/testimonials.php to read real quotes from published authors. 